\title{
Biosynthesis of Variant Medium Chain Acyl-CoA Dehydrogenase in Cultured Fibroblasts from Patients with Medium Chain Acyl-CoA Dehydrogenase Deficiency
}

\author{
YASUYUKI IKEDA, ${ }^{1}$ DANIEL E. HALE, SUSAN M. KEESE, PAUL M. COATES, AND \\ KAY TANAKA \\ Department of Human Genetics, Yale University School of Medicine, New Haven, Connecticut 06510 (Y.I., \\ S.M.K., K.T.) and Department of Pediatrics, University of Pennsylvania School of Medicine and Divisions of \\ Endocrinology/Diabetes (D.E.H.) and Genetics (P.M.C.), The Children's Hospital of Philadelphia, Philadelphia, \\ Pennsylvania 19104
}

\begin{abstract}
We prepared monospecific antiserum in rabbits against medium chain acyl-CoA dehydrogenase (MCAD) purified from rat liver and studied the biosynthesis of MCAD in cultured skin fibroblasts from patients with MCAD deficiency using the antibody. Cells were incubated with [ ${ }^{35}$ S]methionine. The labeled MCAD was immunoprecipitated using the anti-rat MCAD antiserum and Staphylococcus aureus cells and then analyzed by sodium dodecyl sulfate-polyacrylamide gel electrophoresis. We first demonstrated that antirat MCAD antibody crossreacted specifically with human MCAD. In 13 MCADdeficient cell lines tested, the residual MCAD activity ranged from $5-12 \%$ of the mean of normal controls, but the variant MCAD in all of these cells was indistinguishable from the normal human MCAD on the basis of molecular size, indicating that MCAD deficiency in all of these patients is most likely due to point mutation(s) in the MCAD gene. (Pediatr Res 20: 843-847, 1986)
\end{abstract}

\section{Abbreviations}

DNP, dinitrophenol

ETF, electron transfer flavoprotein

FAD, flavin-adenine dinucleotide

IVD, isovaleryl-CoA dehydrogenase

LCAD, long chain acyl-CoA dehydrogenase

MCAD, medium chain acyl-CoA dehydrogenase

NETS, $150 \mathrm{mM} \mathrm{NaCl,} 10 \mathrm{mM}$ EDTA, pH 7.4, 0.5\%

Triton X-100, and $0.25 \%$ SDS

PAGE, polyacrylamide gel electrophoresis

PBS, phosphate-buffered saline

SCAD, short chain acyl-CoA dehydrogenase

SDS, sodium dodecyl sulfate

MCAD deficiency is an inborn error of fatty acid metabolism. MCAD deficiency is clinically identified by fasting intolerance,

Received December 6, 1985; accepted April 21, 1986.

Address for correspondence and reprint requests Kay Tanaka, M.D., Yale University School of Medicine, Department of Human Genetics, 333 Cedar Street, P.O. Box 3333, New Haven, CT 06510.

This work was suported by grants from the National Institutes of Health (AM17453, AM01226, and NS 17752) and March of Dimes (1-378)

1 Present address National Cardiovascular Center Research Institute 5-125 Fujishiro-dai, Suita City 565, Osaka, Japan. recurrent episodes of hypoglycemic coma accompanied by medium chain dicarboxylic aciduria, a failure of ketogenesis, and low plasma and tissue carnitine levels. Since it was first characterized in $1982(1-3)$, at least 30 patients with this disease have been confirmed $(4,5)$ (Hale $\mathrm{D}$, and Coates $\mathrm{P}$, unpublished observations). In some patients, this disease may be severe and fatal. For the most part, however, their epidoses of illness are relatively mild and can be prevented by avoiding prolonged fasting. Biochemically, MCAD deficiency has been demonstrated in liver (2), cultured fibroblasts $(1,3-5)$, and leukocytes (4). However, the molecular aspects of the mutation of the enzyme have not been studied.

MCAD (6) is one of the three acyl-CoA dehydrogenases which catalyze the first reaction step of the $\beta$-oxidation cycles in the catabolism of fatty acids. The two others are SCAD and LCAD $(7,8)$. In addition, two other acyl-CoA dehydrogenases which catalyze dehydrogenation of branched chain acyl-CoAs in the metabolism of the branched chain amino acids are known $(9$, $10)$. We have recently purified MCAD and the four other acylCoA dehydrogenases to homogeneity from rat liver mitochondria, and extensively characterized their physical and biochemical properties (11-13).

All acyl-CoA dehydrogenases share many molecular features $(10-13)$ and catalytic mechanisms (14-16). These enzymes catalyze the removal of one hydrogen each from the $\alpha$ - and $\beta$ positions of appropriate acyl-CoA substrates via the formation of a charge transfer complex (14-16). They require ETF (17) as electron acceptor. In mitochondria, electrons are further transferred to the main mitochondrial electron transport chain via ETF-dehydrogenase and coenzyme Q (18). Each dehydrogenase is a tetramer of identical subunits with a subunit molecular weight ranging from 41 to $45 \mathrm{kDa}$. The subunit molecular weight of rat MCAD is $45 \mathrm{kDa}$. Each subunit contains 1 mol of FAD. We raised antisera in rabbits against the individual rat acyl-CoA dehydrogenases. Each antiserum was monospecific to the corresponding enzyme but did not cross-react with any of the other acyl-CoA dehydrogenases (11-13). In addition, using a cell-free translation system consisting of rabbit reticulocyte lysate directed by rat polysomal RNA and immunoprecipitation, we have shown that like other mitochondrial matrix enzymes encoded by nuclear genes, rat acyl-CoA dehydrogenases are each synthesized in the cytosol as a precursor, 2-4 $\mathrm{kDa}$ larger than the corresponding mature enzymes. The rat precursor MCAD is $49 \mathrm{kDa}, 4 \mathrm{kDa}$ larger than the mature rat MCAD (19). The precursors of MCAD and other acyl-CoA dehydrogenases are then imported into mitochondria by an energy dependent mechanism and finally 
processed to the mature form by cleaving their extended sequence (19). The synthesis of precursor and mature MCAD has been demonstrated in cultured Buffalo rat liver cells in situ by labeling the cells with $\left[{ }^{35} \mathrm{~S}\right]$ methionine in the presence or absence of an inhibitor of mitochondrial energy metabolism such as DNP or rhodamine $6 \mathrm{G}$, and detecting the product using immunoprecipitation and SDS-PAGE (19).

Recently, we have shown that the antirat MCAD antibody specifically cross-reacts with human MCAD and that normal human MCAD is $1 \mathrm{kDa}$ larger than rat MCAD, as measured by the mobility on SDS-PAGE (Ikeda Y, Tanaka K, unpublished observations). By contrast, the sizes of other human acyl-CoA dehydrogenases were the same as those of their rat counterparts. Herein, we report the biosynthesis of normal and variant MCAD in cultured human fibroblasts using $\left[{ }^{35}\right.$ S $]$ methionine labeling, immunoprecipitation, and SDS-PAGE analysis.

\section{MATERIALS AND METHODS}

Materials. L- $\left[{ }^{35} \mathrm{~S}\right] \mathrm{methionine}(600 \mathrm{Ci} / \mathrm{mmol})$ was purchased from Amersham Corp. Inactivated Staphylococcus aureus cells were obtained from Bethesda Research Laboratories. Rhodamine $6 \mathrm{G}$ was procured from Eastman. Cell culture materials were from Gibco.

Sources of cells. The sources of the cell lines, except for two, have been previously reported as listed in the following: $\mathrm{A}, \mathrm{N}-1$ (4); B, B-1 (4); C, B-2 (4); D, T-1 (4); E, J-1 (20); F, W-1 (4); G, M-1 (4); H, H-1 (4); I, K-1 (4); J, A-1 (21); K, R-1 (21); L, F-1 (4); M, 12 (4); 1421 (21), 1475, unpublished; and 1476, unpublished.

Preparation of antibody against MCAD. MCAD was purified to homogeneity from rat liver mitochondria as described in our previous reports (11). Antiserum against rat MCAD was raised in a rabbit and partially purified by twice fractionating with $50 \%$ saturation of ammonium sulfate as previously described (11). The antibody was monospecific to rat (11) and human MCAD. It was capable of precipitating approximately $15 \mu \mathrm{g}$ of the rat MCAD per $100 \mu \mathrm{l}$ antiserum.

Table 1. Acyl-CoA dehydrogenase activities in MCAD- and $L C A D$-deficient fibroblasts

\begin{tabular}{cccc} 
& \multicolumn{4}{c}{ Acyl-CoA dehydrogenase activity } \\
\cline { 2 - 4 } Cell line & $\begin{array}{c}\text { Palmitoyl-CoA } \\
\text { (nmol ETF reduced/min/mg protein) }\end{array}$ & $\begin{array}{c}\text { Octanoyl-CoA } \\
\text { (n) }\end{array}$ \\
\hline A & 2.34 & 0.49 & ND* \\
B & ND & 0.34 & ND \\
C & 1.59 & 0.34 & 0.87 \\
D & 1.90 & 0.27 & 1.04 \\
F & 2.43 & 0.47 & 0.94 \\
G & 1.75 & 0.34 & 0.80 \\
H & 1.99 & 0.22 & 1.18 \\
I & 2.13 & 0.29 & 0.88 \\
L & 2.86 & 0.41 & 0.72 \\
M & 2.14 & 0.31 & ND \\
1421 & 2.21 & 0.28 & 1.07 \\
I475 & 2.00 & 0.22 & 0.90 \\
1476 & 2.01 & 0.29 & 1.43 \\
E & 0.21 & 4.38 & 1.90 \\
J & 0.20 & 3.42 & 2.16 \\
K & 0.18 & 3.22 & 2.42 \\
Control & $2.15 \pm 0.22 \dagger$ & $4.06 \pm 0.40 \dagger$ & $2.11 \pm 0.23 \dagger$ \\
& $(43) \ddagger$ & $(43)$ & $(39)$ \\
\hline
\end{tabular}

Cell lines $\mathrm{E}, \mathrm{J}$, and $\mathrm{K}$ are LCAD-deficient cells. The other cell lines are MCAD-deficient cells.

* Not determined.

$\dagger$ Mean \pm 1 SD.

$\ddagger$ Numbers in parentheses indicate the number of control cell cultures tested.
Labeling of fibroblasts in culture. Fibroblasts were grown in Eagle's minimum essential medium supplemented with $10 \%$ fetal calf serum, nonessential amino acids, and kanamycin (growing medium). They were maintained at $37^{\circ} \mathrm{C}$ in a $5 \% \mathrm{CO}_{2}$ atmosphere. The confluent monolayers of fibroblasts in $6-\mathrm{cm}$ dishes (approximately $5 \times 10^{6}$ cells/dish) were labeled with $\left[{ }^{35} \mathrm{~S}\right]$ methionine $(50-100 \mu \mathrm{Ci})$ in $5 \mathrm{ml}$ of "labeling media" containing $60 \%$ Puck's saline F, $15 \%$ dialyzed fetal calf serum, and $10 \%$ glucose as previously described (22). The dishes were incubated at $37^{\circ} \mathrm{C}$ for $1 \mathrm{~h}$. After removing the labeling medium, cells were washed with PBS and harvested by adding $1 \mathrm{ml}$ of a buffer containing $150 \mathrm{mM} \mathrm{NaCl}, 10 \mathrm{mM}$ EDTA, pH 7.4, 0.5\% Triton $\mathrm{X}-100,0.25 \% \mathrm{SDS}$, and $2 \%$ unlabeled methionine (NETS/ methionine) to each dish. The solubilized cell extract was subjected to immunoprecipitation. When rhodamine $6 \mathrm{G}$ was used, it was added to the medium at a final concentration of $2.1 \mu \mathrm{M}$, $30 \mathrm{~min}$ before the medium was replaced with the labeling medium containing $\left[{ }^{35} \mathrm{~S}\right] \mathrm{methionine}$. The dish was then incubated at $37^{\circ} \mathrm{C}$ for $60 \mathrm{~min}$ in the labeling medium containing the same concentration of rhodamine $6 \mathrm{G}$. The labeling and extraction of cells were performed as described above.

Immunoprecipitation and SDS-PAGE. One $\mathrm{ml}$ of sample prep-

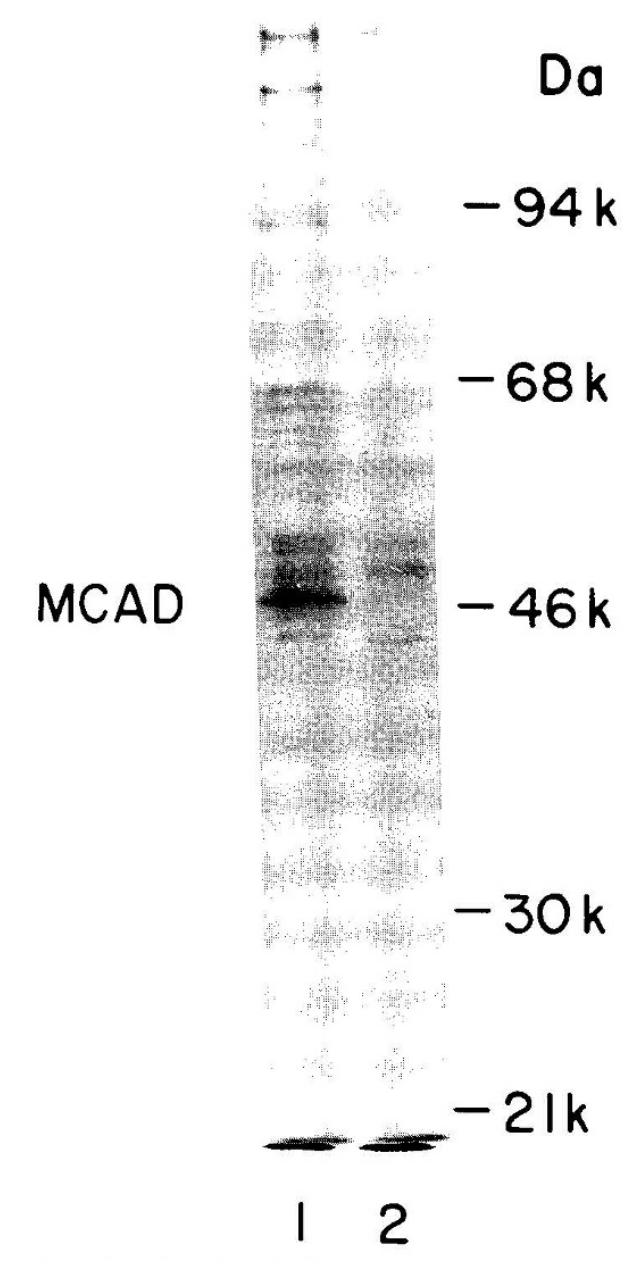

Fig. 1. Slab SDS-PAGE of $\left[{ }^{35} \mathrm{~S}\right]$ methionine-labeled MCAD synthesized in normal cultured human fibroblasts. The confluent monolayers of cells were labeled and the cell extracts were immunoprecipitated by antirat MCAD antiserum $(10 \mu \mathrm{l})$, and the immunoprecipitates were analyzed on $10 \%$ SDS-PAGE as described in "Materials and methods." Lane $1,\left[{ }^{35}\right.$ S $]$ methionine labeled MCAD immunoprecipitated with antirat MCAD antiserum; lane 2, immunoprecipitates from a cell extract to which $7 \mu \mathrm{g}$ of unlabeled pure rat MCAD were added prior to the addition of antiserum (competition experiment). 
aration solubilized in NETS/methionine-buffer was centrifuged for $30 \mathrm{~min}$ at $105,000 \times \mathrm{g}$. The supernatant was incubated at $25^{\circ} \mathrm{C}$ for $30 \mathrm{~min}$ with $100 \mu \mathrm{l}$ of $S$. aureus cell suspension $(10 \%$ w/v) to remove proteins which bind to $S$. aureus cells. After centrifugation, the resulting supernatant was mixed with $10 \mu \mathrm{l}$ of antirat MCAD antibody, and the mixture was allowed to stand at $4^{\circ} \mathrm{C}$ for $12 \mathrm{~h}$. The immune complexes were then recovered by adding 10 volumes of $S$. aureus cell suspension per volume of antibody, followed by centrifugation. Subsequent washes of the immunoprecipitates were performed as described (22). Slab SDS-PAGE was performed using $9 \%$ gels $(0.8 \mathrm{~mm}$ thick) according to the method of Laemmli (23). Gels were stained with Coomassie brilliant blue, treated with Autofluor (National Diagnostics), then dried and fluorographed according to the supplier's directions. X-ray film (XAR-5, Kodak) was used to visualize the labeled protein bands in the fluorographed gels. The following ${ }^{14} \mathrm{C}$-labeled proteins were used as molecular weight markers: phosphorylase b $(94 \mathrm{kDa})$, bovine serum albumin $(68$ $\mathrm{kDa})$, ovalbumin $(46 \mathrm{kDa})$, and $\alpha$-chymotrypsinogen ( $26 \mathrm{kDa})$.

Assay of acyl-CoA dehydrogenases. The assays were performed as previously described (4), essentially according to the method of Frerman and Goodman (24). This method determines acylCoA dehydrogenase activity by measuring the rate of decrease of fluorescence of oxidized ETF at $496 \mathrm{~nm}$, as ETF becomes reduced by the acyl-CoA dehydrogenase-catalyzed electron transfer. Enzyme activity was expressed as nmol ETF reduced per min per mg protein. Protein concentration was determined by the method of Lowry et al. (25).

\section{RESULTS}

Activity of acyl-COA dehydrogenases. Activities of short, medium and long chain acyl-CoA dehydrogenases in 13 MCADdeficient cell lines and three LCAD-deficient cell lines are listed in Table 1 . The MCAD activities in MCAD-deficient cells ranged from 5.4 to $12.1 \%$ of the mean of 43 normal controls while LCAD activities were within a range of 2 SDs from the mean of controls in most of these cells. SCAD activities in these cells were lower than normal, ranging from 37 to $62 \%$ of the mean of 39 controls. By contrast, MCAD and SCAD activities were within normal limits in three LCAD-deficient cell lines while LCAD activities were only 8.0 to $9.4 \%$ of the mean of normal controls.

Biosynthesis of MCAD in normal human fibroblasts. First, cultured normal human fibroblasts were incubated with $\left[{ }^{35} \mathrm{~S}\right]$ methionine in the absence of mitochondrial inhibitor. The labeled products were immunoprecipitated using antirat MCAD antibody and $S$. aureus cells and then analyzed by SDS-PAGE. A sharp labeled band with a molecular weight of $46 \mathrm{kDa}$ was observed as shown in Figure 1, lane 1. We have shown previously that the molecular size of MCAD immunoprecipitated from human liver was $46 \mathrm{kDa}, 1 \mathrm{kDa}$ larger than the size of rat MCAD. The labeled band was not detected in the competition experiment in which an excess of the purified rat MCAD was added prior to the addition of the antibody to compete with a small amount of labeled MCAD for anti-MCAD antibody (lane 2), confirming the identity of the labeled band as MCAD.

Biosynthesis of medium chain acyl-CoA dehydrogenase in the mutant cells. The synthesis of MCAD in the absence of rhodamine $6 \mathrm{G}$ was studied in $11 \mathrm{MCAD}$-deficient cell lines and three LCAD cell lines using the same method. As shown in Figure 2, mutant MCAD were actively synthesized in all 11 MCADdeficient cell lines. The molecular size of the mutant MCAD was identical to the normal MCAD detected in a normal cell line and three LCAD-deficient cell lines.

We then labeled a normal and 12 MCAD-deficient cell lines with $\left.{ }^{35} \mathrm{~S}\right]$ methionine in the presence and absence of rhodamine $6 \mathrm{G}$. A radioactive band of precursor MCAD (molecular weight $50 \mathrm{kDa}$ ), which was $4 \mathrm{kDa}$ larger than the mature MCAD, was detected in the normal cell line (Fig. 3). Also, in each of the 12 MCAD-deficient cell lines, an intensely labeled radioactive band, each $4 \mathrm{kDa}$ larger than the corresponding mature variant MCAD, was detected (Fig. 3). The molecular sizes of the precursor MCAD in mutant cells were all identical to that detected in normal cells. No heterogeneity was observed among the 12 mutant cell lines studied.
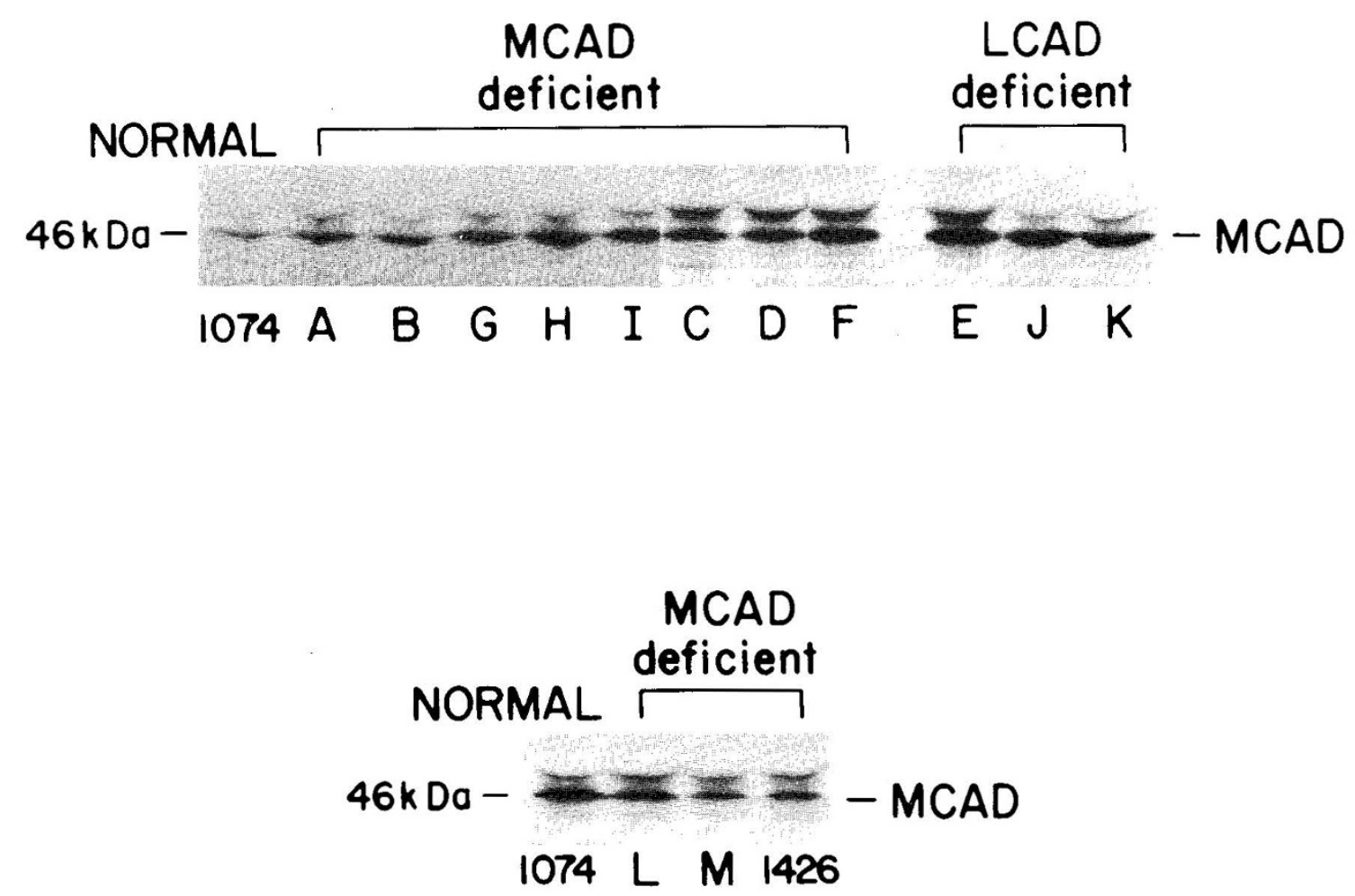

Fig. 2. Electrophoretic analysis of variant MCAD synthesized in 11 MCAD-deficient cells, one control and three LCAD-deficient cells. The band above the MCAD band in each lane is due to a nonspecific protein adsorbed by $S$. aureus cells. 

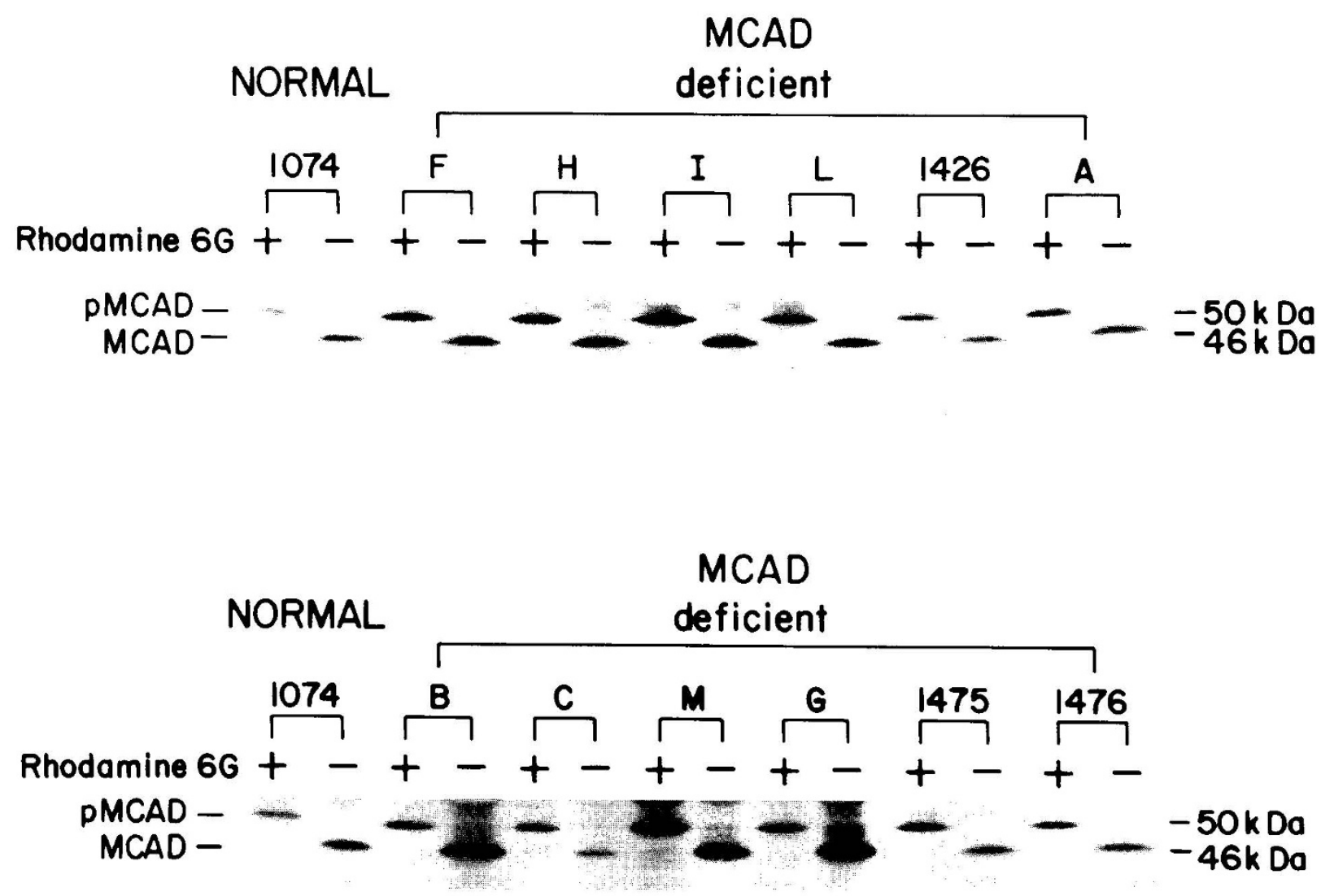

Fig. 3. Electrophoretic analyses of mature variant MCAD and its precursor synthesized in $12 \mathrm{MCAD}$-deficient cell lines. Cells were labeled with $\left[{ }^{35} \mathrm{~S}\right]$ methionine in the presence and absence of $2.1 \mu \mathrm{M}$ rhodamine $6 \mathrm{G}$.

\section{DISCUSSION}

We have shown in this study that normal human MCAD is synthesized as a precursor $(50 \mathrm{kDa}), 4 \mathrm{kDa}$ larger than the mature MCAD (46 kDa). We showed previously that the precursor of rat MCAD (49 $\mathrm{kDa}$ ) was also $4 \mathrm{kDa}$ larger than its mature counterpart $(45 \mathrm{kDa})$. Furthermore, the size difference between the precursor and the mature enzyme was identical in human and rat for IVD (2 kDa) (22) and for the $\alpha$-subunit of ETF (3 $\mathrm{kDa})(26)$. These observations suggest that the extended sequences in the precursor enzymes in humans are similar or identical to those in their rat counterparts.

We examined the synthesis of mutant MCAD in 13 MCADdeficient cell lines. MCAD was actively synthesized in all of these cell lines. The molecular sizes of both precursor and mature forms of MCAD's were identical to those of normal MCAD as determined on SDS-PAGE. There were no recognizable differences in the intensity of labeling and molecular size of MCAD among the 13 MCAD-deficient cell lines studied. This is in contrast to our recent findings on isovaleric acidemia and glutaric aciduria type II cells. We have shown that there are five distinct variant alleles among the 15 isovaleric acidemia cell lines tested. These variant alleles were distinguished based on the ability of the cells to synthesize IVD and on the molecular size of variant that is immuno-cross-reactive to antiserum raised against the rat enzyme (22). Similarly, three distinct variant alleles were detected among three glutaric aciduria type II cell lines due to ETF deficiency based on the ability of the cells to synthesize the ETF $\alpha$-subunit and on the molecular size of the ETF $\alpha$-subunit that is immuno-cross-reactive to antibody against the rat ETF $\alpha$ subunit (26). The lack of heterogeneity in the $13 \mathrm{MCAD}$-deficient cell lines in their ability to synthesize variant MCAD and their similar residual MCAD activity seem to suggest that there is only one variant MCAD allele. Because the size of the variant MCAD is the same as that of normal MCAD, it is likely that this variant allele is due to a point mutation, producing a catalytically incompetent enzyme. However, there is still a possibility that there are multiple variant alleles, each due to a point mutation which occurs at a different position in the gene.

Acknowledgment. The authors thank Dr. Jan Kraus for useful suggestions.

\section{REFERENCES}

1. Kolvraa S, Gregersen N, Christiansen E, Hobolth $\mathrm{N} 1982$ In vitro fibroblast studies in a patient with $\mathrm{C}_{6}-\mathrm{C}_{10}$-dicarboxylic aciduria: Evidence for a defect in general acyl-CoA dehydrogenase. Clin Chim Acta 126:53-67

2. Stanley CA, Hale DE, Coates PM, Hall CL, Corkey BE, Yang W, Kelley RI, Gonzales EL, Williamson JR, Baker L 1983 Medium chain acyl-CoA dehydrogenase deficiency in children with non-ketotic hypoglycemia and low carnitine levels. Pediatr Res 17:877-884

3. Rhead WJ, Amendt BA, Fritchman KS, Felts SJ 1983 Dicarboxylic aciduria: deficient $\left[1-{ }^{14} \mathrm{C}\right]$ octanoate oxidation and medium chain acyl-CoA dehydrogenase in fibroblasts. Science 221:73-75

4. Coates PM, Hale DE, Stanley CA, Corkey BE, Cortner JA 1985 Genetic deficiency of medium chain acyl-Coenzyme A dehydrogenase: studies in cultured skin fibroblasts and peripheral mononuclear leukocytes. Pediatr Res 19:672-676

5. Amendt BA, Rhead WJ 1985 Catalytic defect of medium-chain acyl-co-enzyme A dehydrogenase deficiency. J Clin Invest 76:963-969

6. Crane FL, Mii S, Hauge JG, Green DE, Beinert H 1956 On the mechanism of dehydrogenation of fatty acyl derivatives of Coenzyme A: (I) The general fatty acyl Coenzyme A dehydrogenase. J Biol Chem 218:701-716

7. Green DE, Mii S, Mahler HR, Bock RM 1954 Studies of the fatty acid oxidizing system of animal tissues: (III) Butyryl Coenzyme A dehydrogenase. J Biol Chem 218:1-12

8. Hauge J, Crane FL, Beinert $\mathrm{H} 1956$ On the mechanism of dehydrogenation of fatty acyl derivatives of Coenzyme A: (III) Palmitoyl-CoA dehydrogenase. $J$ Biol Chem 219:727-733

9. Noda C, Rhead W, Tanaka K 1980 Isovaleryl-CoA dehydrogenase: demonstration in rat liver mitochondria by ion exchange chromatography and isoelectric focusing. Proc Natl Acad Sci USA 77:2646-2650

10. Ikeda X, Dabrowski D, Tanaka K 1983 Separation and properties of five 
distinct acyl-CoA dehydrogenases from rat liver mitochondria: identification of a new 2-methyl-branched chain acyl-CoA dehydrogenase. J Biol Chem 258:1066-1076

11. Ikeda Y, Ikeda KO, Tanaka K 1985 Purification and characterization of short chain, medium chain, and long chain acyl-CoA dehydrogenases from rat liver mitochondria: Isolation of the holo- and apoenzymes and conversion of the apoenzyme to the holoenzyme. J Biol Chem 260:1311-1325

12. Ikeda Y, Tanaka K 1983 Purification and characterization of isovaleryl-CoA dehydrogenase from rat liver mitochondria. J Biol Chem 258:1077-1085

13. Ikeda X, Tanaka K 1983 Purification and characterization of 2-methylbranched chain acyl-CoA dehydrogenase, an enzyme involved in the isoleucine and valine metabolism, from rat liver mitochondria. J Biol Chem 258:9477-9487

14. Ikeda Y, Hine DG, Okamura-Ikeda K, Tanaka K 1985 Mechanism of action of short chain, medium chain, and long chain acyl-CoA dehydrogenases: direct evidence for carbanion formation as an intermediate step using enzyme-catalyzed C-2 proton/deuteron exchange in the absence of C-3 exchange. J Biol Chem 260:1326-1337

15. Okamura-Ikeda K, Ikeda Y, Tanaka K 1985 An essential cysteine residue located in the vicinity of the FAD-binding site in short chain, medium chain, and long chain acyl-CoA dehydrogenases from rat liver mitochondria. J Biol Chem 260:1338-1345

16. Ikeda Y, Okamura-Ikeda K, Tanaka K 1985 Spectroscopic analysis of the interaction of rat liver short chain, medium chain, and long chain acyl-CoA dehydrogenases with acyl-CoA's. Biochemistry 24:7192-7199

17. Crane FL, Beinert $H 1956$ On the mechanism of dehydrogenation of fatty acyl derivatives of coenzyme A: the electron-transferring flavoprotein. $\mathbf{J}$ Biol
Chem 218:7171-731

18. Ruzicka FJ, Beinert H 1977 A new iron-sulfur protein of the respiratory chain: a component of the fatty acid $\beta$ oxidation pathway. J Biol Chem 252:84408445

19. Ikeda $\mathrm{X}$, Fenton WA, Tanaka K 1984 In vitro translation and posttranslational processing of four mitochondrial acyl-CoA dehydrogenases. Fed Proc 43:2024 (abstr)

20. Hale DE, Batshaw ML, Coates PM, Frerman FE, Goodman SI, Singh I, Stanley CA 1985 Long-chain acyl coenzyme A dehydrogenase deficiency: An inherited case of nonketotic hypoglycemia. Pediatr Res 19:666-671

21. Del Valle JA, Garcia MJ, Merinero B, Perez-Cerda C, Jimenez RA, Ugarte M 1984 A new patient with dicarboxylic aciduria suggestive of medium-chain acyl-CoA dehydrogenase deficiency presenting as Reye's syndrome. $J$ Inherited Metab Dis 7:62-64

22. Ikeda Y, Keese SM, Tanaka K 1985 Molecular heterogeneity of mutant isovaleryl-CoA dehydrogenase in cultured isovaleric acidemia fibroblasts. Proc Natl Acad Sci USA 82:7081-7085

23. Laemmli UK 1970 Cleavage of structural proteins during the assembly of the head of bacteriophage T4. Nature 227:680-685

24. Frerman EF, Goodman SI 1985 Fluorometric assay of acyl-CoA dehydrogenase in normal and mutant fibroblasts. Biochem Med 33:38-44

25. Lowry OH, Rosebrough NJ, Farr AL, Randall RJ 1951 Protein measurement with the Folin phenol reagent. J Biol Chem 193:265-275

26. Ikeda Y, Keese SM, Tanaka K 1986 Biosynthesis of electron transfer flavoprotein in a cell free system and in cultured human fibroblasts: a defect in the $\alpha$-subunit synthesis is a primary lesion in glutaric aciduria type II. J Clin Invest (in press) 